\title{
New PRSS1 and common CFTR mutations in a child with acute recurrent pancreatitis, could be considered an "Hereditary" form of pancreatitis?
}

\author{
Vito D Corleto ${ }^{1,3^{*}}$, Stefano Gambardella ${ }^{2,5 \dagger}$, Francesca Gullotta ${ }^{2}$, Maria R D'Apice ${ }^{2}$, Matteo Piciucchi ${ }^{1}$, Elena Galli ${ }^{3}$, \\ Vincenzina Lucidi ${ }^{4}$, Giuseppe Novelli ${ }^{2,5}$, Gianfranco Delle Fave ${ }^{1}$
}

\begin{abstract}
Background: acute recurrent pancreatitis is a complex multigenic disease, the diagnosis is even more difficult when this disease develops in a child.

Case Presentation: a 6-years old boy, hospitalized with epigastric pain radiating to the back showed high serum levels of serum amylase, lipase, CRP and erythrosedimentation rate. Several similar milder episodes of pain, followed by quick recovery and complete disappearance of symptoms were reported during the previous 13 months. The child was medically treated and after 7 days with normal clinic and laboratory tests was discharged with a hypolipidic diet. All the known aetiologic hypotheses were excluded by anamnestic investigation, clinical observation and biochemical evaluation, whereas, anatomic abnormality were excluded by a secretin stimulated magnetic resonance (MRI). At the last follow-up visit, (11 months later), the child showed a normal body weight and anthropometric profile, without further abdominal pain. Mutation screening for coding regions of PRSS1, SPINK1, CFTR and the new hereditary pancreatitis-associated chymotrypsin C (CTRC) genes showed a novel variation, C.541A > $\mathrm{G}$ (p.S181G), in the exon 4 of PRSS1 gene and the classical CF p.F508del mutation in the CFTR. Both mutations were present in his clinically normal mother and absent in the patient's father.

Conclusions: this report extend the spectrum of PRSS1 mutations, however, the absence of family history of pancreatitis leaves the present case without the hallmark of the hereditary origin of pancreatitis. At the present knowledge it can be only stated that the combined genotype CFTR (F508del)/PRSS1 (S181G) is associated to a mild phenotype of acute recurrent pancreatitis in this child without any further conclusion on its pathogenetic role or prediction on the course of the disease.
\end{abstract}

\section{Background}

Hereditary Pancreatitis (HP) (OMIM \#167800) is a rare autosomal dominant disorder with about $80 \%$ of penetrance. The clinical features of HP patients consist in attacks of acute pancreatitis, that in $\sim 80 \%$ of individuals starts before 20 years of age (median age 10 years). Progression to chronic pancreatitis also occurs in about 50\% of patients and pancreatic cancer may develop by 15 years of age in about $\sim 40 \%$ of affected individuals [1,2]. In 1996, a correlation was first reported between the development

\footnotetext{
* Correspondence: vito.corleto@uniroma1.it

+ Contributed equally

'Dept. of Digestive and Liver Disease, II School of Medicine, University "La Sapienza", Rome, Italy

Full list of author information is available at the end of the article
}

of the disorder and hereditary factors with the PRSS1 gene, that encodes for the human cationic trypsinogen $[3,4]$. Mutations and copy number variation (CNV) in the PRSS1 gene are responsible for the increase of autocatalytic conversion of trypsinogen to active trypsin that leads to autodigestion of the organ $[5,6]$.

Chronic pancreatitis has also been associated with mutations in other genes such as SPINK 1 (serine protease inhibitor Kazal Type I) [7], CFTR (Cystic Fibrosis transmembrane conductance regulator) [8], CTRC (chymotrypsin C) [9]. Contemporary mutations, in these genes, trigger a distinctly greater risk of developing chronic pancreatitis [10-12]. While the polymorphism p.G191R in PRSS2 (cationic trypsinogen type 2) gene protects against chronic pancreatitis [13]. 
The present report focuses on the finding of a new heterozygous mutation in the PRSS1 gene, associated with p.F508del mutation in CFTR, in a child presenting acute recurrent pancreatitis.

\section{Case Presentation}

The case is described of a 6-year-old boy, examined in the Emergency Department on account of acute abdominal pain, intense nausea and mild fever $\left(37.5^{\circ} \mathrm{C}\right)$. The clinical history revealed 6 similar episodes during the previous 13 months, some managed at home and other with brief hospitalization. During the very first episode in which he also presented a white blood count of 22,000 ( $88 \%$ neutrophils), appendicectomy was performed. A review of previous medical charts revealed that amylase had been evaluated only twice in the past and, on both occasions, it was slightly increased (twice the normal value). However, no further investigation had been performed due to rapid recovery and complete disappearance of abdominal pain. When coming to our attention, the boy appeared to be suffering, with knees drawn up to his chest, and with epigastric pain radiating to his back, of post-prandial onset. Furthermore, the child presented moderate abdominal distension, however, all vital signs were within normal limits. Laboratory studies were all within the normal range, with the exception of serum amylase which was 1373 U/L (n.v. 0-95 U/L), lipase 1050 U/L (n.v. 13-60 U/L), C-reactive protein (CRP) $95 \mathrm{mg} / \mathrm{L}$ (n.v. $0-10 \mathrm{mg} / \mathrm{L}$ ), erythrosedimentation rate (ESR) $74 \mathrm{~mm} / \mathrm{h}$ (n.v. $0-20 \mathrm{~mm} / \mathrm{h}$ ). The child was treated with intravenous (i.v.) fluids plus $20 \mathrm{mg}$ of proton pump inhibitor (PPI) i.v. An abdominal sonogram showed increased pancreatic volume with diffuse oedema, gallbladder was normal. The following day, laboratory tests showed overall decreased values: amylase $650 \mathrm{U} / \mathrm{L}$, lipase $350 \mathrm{U} / \mathrm{L}$, CRP $30 \mathrm{mg} / \mathrm{L}$. Fluids i.v. were administered for 4 days after which amylase, lipase, CRP and ESR returned close to normal values and a liquid light meal was administered with good results. After 7 days of hospitalization, with normal laboratory tests and without abdominal pain, the child was discharged with a hypolipidic diet, $20 \mathrm{mg}$ PPI daily and pancreatic enzyme supplementation $(10,000 \mathrm{U}$ $\times 6 /$ day) per os. both for two more weeks. Taking into consideration all the aetiologic hypotheses, blunt trauma, metabolic, infectious, drug and systemic causes were excluded, by means of accurate anamnestic investigations and clinical observations and by further laboratory evaluations (calcium, glucose and triglycerides were always normal; Mumps, Cytomegalovirus, Coxsackie B, Herpes Simple virus antibodies were negative). In the attempt to exclude any anatomic abnormality, secretin-stimulated magnetic resonance imaging (MRI) of the pancreas was programmed as an outpatient. At follow-up visits, the child presented stable body weight, good appearance, with no further episodes of abdominal pain, continuing a strictly controlled of hypolipid diet. The secretin MRI, performed 2 months later, showed an overall increased thickness of the parenchyma of the entire pancreas with aspecific irregular signal intensity in the head region. Following secretin stimulation, the main pancreatic duct appeared to be normal, with a normal papilla in the second part of the duodenum that was normally filled, 10 minutes after the secretin infusion. At the last followup visit, $\sim 11$ months after the last acute pancreatic attach, the child presented a normal anthropometric profile with normal body weight, and no further episodes of abdominal pain were reported. However, two new short episodes of abdominal pain have been recently reported with a slight increase of only lipase levels $(110 \mathrm{U} / \mathrm{L} ;$ n.v. 13-60) following the last one.

Given the unexplained episode of pancreatitis in a child, it was decided to investigate point mutations in the cationic trypsinogen gene (PRSS1) underlying HP, although no data were available suggesting familial pancreatitis in this patient. CFTR, SPINK-1 and the new $\mathrm{HP}$-associated chymotrypsin $\mathrm{C}(C T R C)$ gene were also analysed. While genetic testing revealed normal SPINK1 and CTRC genes, a novel heterozygous variation, c.541A > G (p.S181G), in exon 4 of PRSS1 gene was revealed (Figure 1). This transition was never been detected in 100 unrelated healthy controls, suggesting that this variation is a putative mutation (http://www. ncbi.nlm.nih.gov/sutils/blink.cgi?mode=result\&pid). The patient also showed the classic p.F508del mutation, in a heterozygous state, in the CFTR gene. However, no other nucleotide variations or genomic rearrangements were detected in this gene following careful examination. Both mutations were absent in the patient's father but present in his clinically healthy mother.

To explain the discordance in phenotype, between mother and proband, the following possibilities were taken into consideration: i) presence, in the proband or the father's genome, of gross deletions/insertions in the pancreatitis causative genes; ii) presence of active modifier factors such as protective polymorphism p.G191R in the PRSS2 gene; iii) non paternity, and iv) environmental effects.

To exclude the first hypothesis, we applied aCGH (array-based Comparative Genomic Hybridization) to detect macro deletions and macro insertions on the entire genome of the father's and proband's DNA. No significant alterations were detected (data not shown). The second and third hypotheses were ruled out by complete sequence analysis of the PRSS2 gene and testing of paternal micro-satellites (data not shown). Furthermore, a detailed dietary history of the child showed high frequency of consumption of fat food prior to the onset of the acute pancreatitis episodes. 


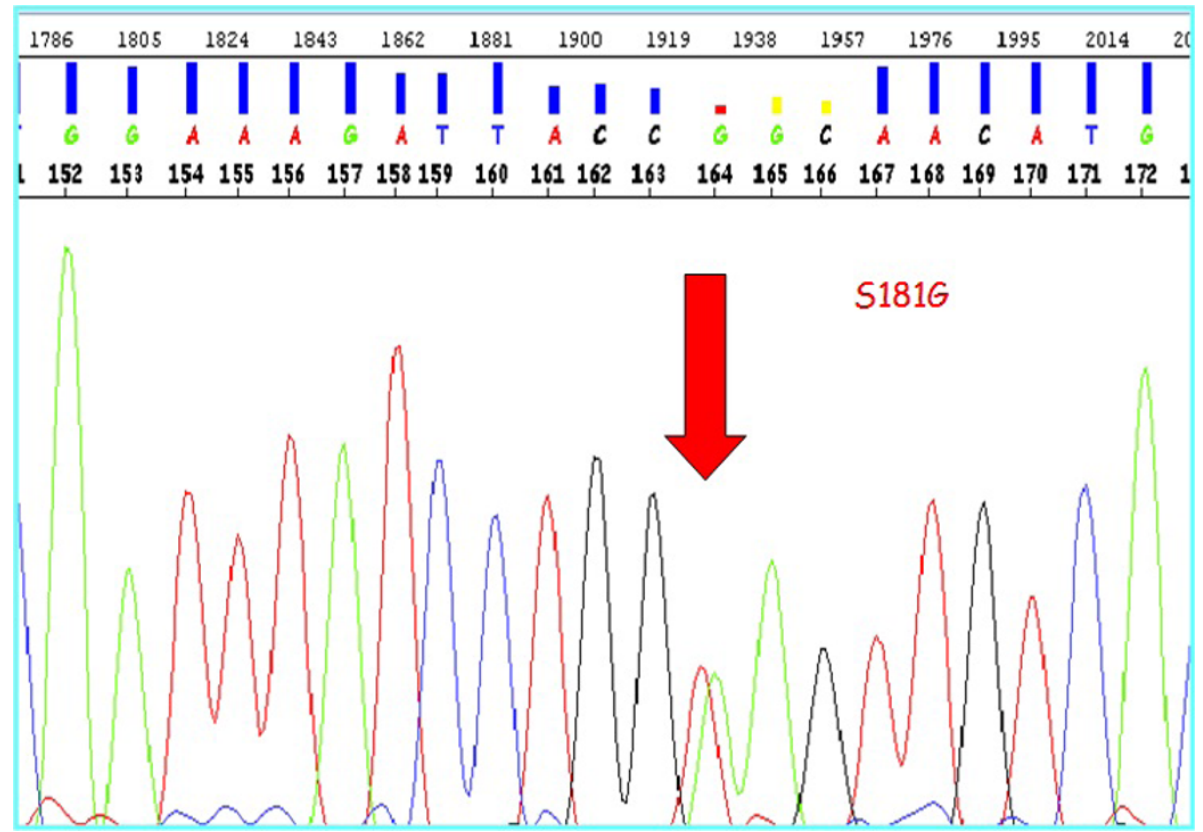

Figure 1 Sequence chromatogram of the PRSS1 mutation p.S181G.

\section{Methods}

The parents were constantly informed regarding the interpretation of the clinical and genetic investigations and always gave their written consent both to the procedures and the laboratory investigations. PRSS1, PRSS2, SPINK1, CTRC and CFTR coding regions amplification and sequencing were performed on an ABI 3130 Genetic analyzer, according to previously reported conditions [7,9,13-15], (Applied Biosystems; Foster City, CA, USA).

Analysis of CFTR rearrangements was performed using a quantitative PCR followed by capillary electrophoresis (Multiplex ligation-dependent probe amplification, MLPA SALSA Kit, MRC-Holland, The Netherlands). aCGH was performed by Agilent's Oligonucleotide Array-Based CGH for Genomic DNA $4 \times 44 \mathrm{~K}$.

\section{Discussion and Conclusions}

The present case represents a rare condition in a child with recurrent acute pancreatitis allegedly determined or favoured by a compound heterozygous mutations, p.F508del in CFTR and a novel maternal transmitted mutation, p.S181G, in exon 4 of the PRSS1. This report potentially extends the spectrum of the PRSS1 mutation. In fact, all pancreatitis-associated PRSS1 mutations discovered appear to cluster in the N-terminal half of the molecule encoded by exons 2 and 3 . Whereas, the present p.S181G is the first mutation detected in exon 4 corresponding to an amino acid position inside two disulphide bridges, amino acids: 139-206 and 171-185.
Although it is well known that chronic pancreatitis is predisposed by heterozygosity for CFTR mutations, little is known about the combination of CFTR mutations with PRSS1 or SPINK1 mutations. To date, only a few cases have demonstrated that pancreatitis is caused by simultaneous CFTR and SPINK1 mutations (5.5\%), of PRSS1 and SPINK1 (1.3\%), and of PRSS1 and CFTR (1.8\%). No information concerning clinical features of these patients are available. Between $60 \%$ and $80 \%$ of HP patients carry a pathogenic PRSS1 mutation. Lower penetrance and perhaps, in some cases, modifier genes have been identified, particularly the CFTR and SPINK1 [16].

In the present report, the combined genotype F508del/ S181G is associated with acute pancreatitis episodes in the 6-year-old proband, but not in his 37-year-old mother, who carries the same genotype, but without any pancreatic symptoms, biochemical or ultrasound pancreatic alterations.

Following the experimental exclusion of gross deletions/insertions in the pancreatitis causative genes in the father, of a case of non paternity, and of the presence of other mutations in pancreatitis relevant genes, it is tempting to suggest that the phenotypic discordance may be due to unknown combination of genetic and/or environmental factors.

Therefore, it could be a potential late onset of pancreatic disease in the proband's mother, or a case of incomplete penetrance of a genotype composed by two mutations (up to $20 \%$ of PRSS1 gene carriers may remain symptom-free) [14]. In addition, it cannot be excluded that this genotype- 
phenotype discordance is due to unidentified modifier genes, relevant for the development of pancreatitis. On the other hand, the finding that a hypolipidic diet has been able to prevent any further pancreatic attack, suggests that diet could have a great importance between the proband and his mother phenotype. Similar cases of phenotypic discordance represent an unresolved genetic aspect that will be addressed in the future i.e. why some carriers of PRSS1 mutation remain completely healthy whereas their relatives with the same mutation develop various grade of disease [1]. However, the absence of family history of pancreatitis leaves the present case without the hallmark of the hereditary origin of pancreatitis in the present child. In conclusion, functional studies are mandatory to understand if and/or how PRSS1 mutation S181G could be involved in determining recurrent pancreatitis or if it needs to be combined with other HP causing genes such as CFTR mutations. At the moment, the combined genotype F508del/S181G could be only associated to a mild phenotype of acute recurrent pancreatitis as happened in the present child. Moreover, on the base of the present report we cannot establish whether PRSS1 S181G gene mutation has a pathogenetic role on the child pancreatic disease nor any prediction on the course of the disease.

\section{Acknowledgements}

This study was supported by the "Fondazione per la Ricerca sulla Fibrosi Cistica" grant 23/2006 (Verona, Italy). The present report has been presented at the XXXII annual meeting of the "Associazione Italiana Studio Pancreas" (AISP), 2-4 October 2008, Montecatini Terme, (PT).

Authors are grateful to Mrs. Marian Shields for help with the English manuscript.

Authors declare no conflict of interest

\section{Author details}

${ }^{1}$ Dept. of Digestive and Liver Disease, II School of Medicine, University "La Sapienza", Rome, Italy. 'Dept. of Biopathology and Diagnostic Imaging, School of Medicine, University of Tor Vergata, Rome, Italy. ${ }^{3}$ Research Centre S. Pietro, Ospedale S. Pietro, Rome, Italy. ${ }^{4}$ Dept. of Pediatrics, Ospedale Bambino Gesù, Rome, Italy. ${ }^{5}$ Fondazione Livio Patrizi, Rome, Italy.

\section{Authors' contributions}

VDC and SG design and drafted the manuscript and carried out the molecular genetic studies; FG, MRD participated in the molecular genetic studies and sequence alignment; MP, EG and VL followed the clinical part of the study; GN and GDF conceived of the study and its coordination. All authors read and approved the final manuscript.

Received: 25 February 2010 Accepted: 15 October 2010 Published: 15 October 2010

\section{References}

1. Rosendahl J, Bödeker H, Mössner J, Teich N: Hereditary chronic pancreatitis. Orphanet J Rare Dis 2007, 2:1

2. Charnley RM: Hereditary pancreatitis. World J Gastroenterol 2003, 9:1-4.

3. Whitcomb DC, Gorry MC, Preston RA, Furey W, Sossenheimer MJ, Ulrich CD, Martin SP, Gates LK Jr, Amann ST, Toskes PP, Liddle R, McGrath K, Uomo G, Post JC, Ehrlich GD: Hereditary pancreatitis is caused by a mutation in the cationic trypsinogen gene. Nat Genet 1996, 14:141-5.

4. Whitcomb DC, Preston RA, Aston CE, Sossenheimer MJ, Barua PS, Zhang Y, Wong-Chong A, White GJ, Wood PG, Gates LK Jr, Ulrich C, Martin SP,
Post JC, Ehrlich GD: A gene for hereditary pancreatitis maps to chromosome 7q35. Gastroenterology 1996, 110:1975-80.

5. Le Maréchal C, Masson E, Chen JM, Morel F, Ruszniewski P, Levy P, Férec C: Hereditary pancreatitis caused by triplication of the trypsinogen locus. Nat Genet 2006, 38:1372-4.

6. Masson E, Le Maréchal C, Chandak GR, Lamoril J, Bezieau S, Mahurkar S, Bhaskar S, Reddy DN, Chen JM, Férec C: Trypsinogen copy number mutations in patients with idiopathic chronic pancreatitis. Clin Gastroenterol Hepatol 2008, 6:82-8.

7. Witt H, Luck W, Hennies HC, Classen M, Kage A, Lass U, Landt O, Becker M: Mutation in the gene encoding the serine protease inhibitor, Kazal type 1 are associated with chronic pancreatitis. Nat Genet 2000, 25:213-6.

8. Sharer N, Schwarz M, Malone G, Howarth A, Painter J, Super M, Braganza J: Mutations of the cystic fibrosis gene in patients with chronic pancreatitis. N Engl J Med 1998, 339:645-52.

9. Masson $E_{1}$ Chen JM, Scotet $V$, Le Maréchal C, Férec $C$ : Association of rare chymotrypsinogen $C$ (CTRC) gene variations in patients with idiopathic chronic pancreatitis. Hum Genet 2008, 123:83-91.

10. Chandal GR, Idris MM, Reddy KR, Mani KR, Bhaskar S, Rao GV, Singh L: Absence of PRSS1 mutations and association of SPINK-1 trypsin inhibitor mutations in hereditary and non-hereditary chronic pancreatitis. Gut 2004, 53:723-8.

11. Sobczynska-Tomaszewska A, Bak D, Oralewska B, Oracz G, Norek A, Czerska K, Mazurczak T, Teisseyre M, Socha J, Zagulski M, Bal J: Analyses of CFTR, SPINK-1, PRSS1 and AAT mutations in children with acute or chronic pancreatitis. J Pediatric Gastroent Nutrition 2006, 43:299-306.

12. Keiles S, Kammesheidt A: Identification of CFTR, PRSS1, and SPINK1 mutations in 381 patients with pancreatitis. Pancreas 2006, 33:221-227.

13. Witt H, Sahin-Tóth M, Landt O, Chen JM, Kähne T, Drenth JP, Kukor Z, Szepessy E, Halangk W, Dahm S, Rohde K, Schulz HU, Le Maréchal C, Akar N, Ammann RW, Truninger K, Bargetzi M, Bhatia E, Castellani C, Cavestro GM, Cerny M, Destro-Bisol G, Spedini G, Eiberg H, Jansen JB, Koudova M, Rausova E, Macek M Jr, Malats N, Real FX: A degradationsensitive anionic trypsinogen (PRSS2) variant protects against chronic pancreatitis. Nat Genet 2006, 38:668-73.

14. Chen JM, Piepoli Bis A, Le Bodic L, Ruszniewski P, Robaszkiewicz M Deprez PH, Raguenes O, Quere I, Andriulli A, Ferec C: Mutational screening of the cationic trypsinogen gene in a large cohort of subjects with idiopathic chronic pancreatitis. Clin Genet 2001, 59:189-193.

15. D'Apice MR, Gambardella S, Bengala M, Russo S, Nardone AM, Lucidi V, Sangiuolo F, Novelli G: Molecular analysis using DHPLC of cystic fibrosis: increase of the mutation detection rate among the affected population in Central Italy. BMC Med Genet 2004, 5:8.

16. Ellis I: Genetic counseling for hereditary pancreatitis the role of molecular genetics testing for the cationic trypsinogen gene, cystic fibrosis and serine protease inhibitor Kazal type 1. Gastroenterol Clin N Am 2004, 33:839-54.

\section{Pre-publication history}

The pre-publication history for this paper can be accessed here: http://www.biomedcentral.com/1471-230X/10/119/prepub

doi:10.1186/1471-230X-10-119

Cite this article as: Corleto et al:: New PRSS1 and common CFTR mutations in a child with acute recurrent pancreatitis, could be considered an "Hereditary" form of pancreatitis? BMC Gastroenterology 2010 10:119. 